\title{
KAJIAN UJI TARIK BETON HVFA MEMADAT SENDIRI TERHADAP BETON NORMAL
}

\author{
Faisal Arya Yudhanto' ${ }^{1)}$, Agus Setiya Budi' ${ }^{2}$, Halwan Alfisa Saifullah ${ }^{3)}$ \\ 1) Mahasiswa Fakultas Teknik, Prodi Teknik Sipil, Universitas Sebelas Maret \\ 2) Pengajar Fakultas Teknik, Prodi Teknik Sipil, Universitas Sebelas Maret \\ 3) Pengajar Fakultas Teknik, Prodi Teknik Sipil, Universitas Sebelas Maret \\ Jl. Ir. Sutami 36A, Kentingan Surakarta 57126; Telp. (0271) 634524, Fax 662118 \\ Email : yudhanto.faisal@gmail.com
}

\begin{abstract}
Fly ash is an industrial waste produced from coal combustion. Consists of fine particles, with a high content of silica (SiO2). So that it can be used as pozzolanic material as a substitute for cement which is a binder in making concrete. The use of fly ash in an amount greater than $50 \%$ is called the High Volume Fly Ash Concrete (HVFAC). To overcome compaction problems that are not optimal during the casting, the HV FAC concept is combined with Self Compacting Concrete (SCC). This study examines the effect of using 50\% and 60\% fly ash levels on the tensile strength of concrete materials. By examining several parameters, that are the relationship of load-displacement, linear elastic fracture energy and elastic modulus. The experiments are carried out on $10 \times 10 \times 40 \mathrm{~cm}$ dimension concrete, with 50\% and $60 \%$ fly ash content. Tested with uniaxial tensile loads. Concrete quality plan is $30 \mathrm{MPa}$. The characteristics of HVFA-SCC compared to normal concrete at 28 days. From the results of the study concluded, HVFA-SCC has a greater stiffness than normal concrete, as evidenced by the greater modulus elasticity. Right before concrete breaks, HVFA-SCC produces a larger linear elastic fracture energy that forms a better crack signal before the concrete breaks.
\end{abstract}

Keywords: direct tensile strength, fly ash, HVFA-SCC

\begin{abstract}
Abstrak
Fly ash merupakan limbah industri yang dihasilkan dari pembakaran batu bara. Terdiri dari partikel yang halus, dengan kandungan silica ( $\mathrm{SiO} 2)$ yang tinggi. Sehingga dapat dimanfaatkan sebagai bahan pozzolan sebagai pengganti semen yang merupakan bahan pengikat dalam pembuatan beton. Penggunaan fly ash dalam jumlah lebih besar dari 50\% disebut dengan High Volume Fly Ash Concrete (HVFAC). Untuk mengatasi permasalahan pemadatan yang kurang optimal saat pengecoran, konsep HVFAC dipadukan dengan Self Compacting Concrete (SCC). Penelitian ini mengkaji pengaruh penggunaan kadar fly ash $50 \%$ dan 60\% terhadap kuat tarik material beton. Dengan mengkaji beberapa parameter, yaitu hubungan load-displacement, energi fraktur elastik linear dan modulus elastisitas. Eksperimen dilakukan pada beton berdimensi 10x10x40 cm, dengan kadar fly ash 50\% dan 60\%. Diuji dengan beban tarik secara uniaxial. Rencana mutu beton $30 \mathrm{MPa}$. Karakteristik HVFA-SCC lalu dibandingkan dengan beton normal usia 28 hari. Dari hasil penelitian diperoleh kesimpulan, HVFA-SCC memiliki kekakuan lebih besar dari beton normal, dibuktikan dengan nilai modulus elastisitas yang lebih besar. Tepat sebelum beton putus, HVFA-SCC menghasilkan energi fraktur elastik linear yang lebih besar sehingga membentuk sinyal retak yang lebih baik sebelum terjadinya putus beton.
\end{abstract}

Kata Kunci : kuat tarik langsung, fly ash, HVFA-SCC

\section{PENDAHULUAN}

Perkembangan dunia konstruksi di era modern menjadi tantangan bagi para ilmuwan untuk memberikan terobosan teknologi yang dapat memberikan efisiensi dan optimalisasi pada setiap pekerjaan, baik dalam metode pelaksanaan maupun material penyusunnya. Terlebih dalam teknologi beton, konstruksi sekarang ini menuntut mutu beton yang tinggi dengan tetap menjaga workabilitas (kemudahan dalam pengerjaan) dan penggunaan bahan yang ramah lingkungan guna mewujudkan konstruksi berkelanjutan. Beton banyak dipilih dalam pembangunan infrastruktur karena mempunyai banyak kelebihan. Diantaranya sifat workability yang tinggi, nilai desak yang baik, tahan terhadap api, serta memiliki sifat durability yang tinggi. Dan dalam perkembangannya muncul banyak penelitian atau kajian mengenai beton yang ramah lingkungan, serta beton yang dapat mendukung perkembangan konstruksi yang berkelanjutan.

Semakin banyak produksi beton maka semakin banyak pula produksi semen yang dihasilkan. Tentunya kenyataan ini sangat berbeda terhadap konsep ramah lingkungan. Penggunaan semen dalam produksi beton memicu terjadinya pemanasan global (global warming) dan timbulnya efek rumah kaca (green house effect). Mengingat proses produksi satu ton semen menghasilkan CO2 setara dengan 0,55 ton dan memerlukan bahan bakar carbon yang akan pula menghasilkan emisi CO2 sebanyak 0,45 ton (Davidovits, 1994). Pada tahun 2018 diperkirakan produksi semen menyumbang sekitar $7 \%$ dari emisi CO2 global (Energies, 2019). 
Beberapa solusi yang banyak dikembangkan untuk mengurangi emisi $\mathrm{CO} 2$ adalah penggunaan fly ash sebagai substitusi sebagian dari semen, yang diharapkan bisa menjadi campuran yang ramah lingkungan. Abu terbang merupakan limbah pembakaran batu bara yang butirannya lebih halus daripada semen portland, yang mempunyai sifatsifat hidrolik. Fly ash mempunyai sifat kimia berupa silica dan alumina mencapai $80 \%$, sebagai material pengganti guna mengurangi jumlah semen. Kandungan tersebut yang berfungsi sebagai bahan pengikat dalam pembuatan beton, atau sifat pozzolan sama seperti sifat semen. Penggunaan fly ash sebagai substituen semen dalam campuran beton dengan kadar yang cukup besar $(>50 \%)$ dari berat semen. Konsep tersebut lebih dikenal dengan High Volume Fy Ash Concrete (HVFAC). Dengan menggunakan kadar fly ash 50\% sangat memungkinkan untuk mendapatkan beton yang mudah dikerjakan (workability), berkualitas tinggi (goodperformance), dan daya tahan tinggi (durability) (Kumar Mehta, 2006).

Untuk mengatasi permasalahan pemadatan yang kurang optimal saat pengecoran, konsep HVFAC dipadukan dengan Self Compacting Concrete (SCC). Beton memadat mandiri atau Self Compacting Concrete (SCC) memanfaatkan komposisi agregat yang digunakan, bentuk dan ukuran bahan campuran pasta serta kadar superplasticizer. Dengan tujuan mencapai kelecakan dan konsistensi yang menjadikan beton mudah di cor ke dalam cetakan dan celah di sekeliling tulangan dengan berbagai kondisi pelaksanaan pengecoran yang harus dilakukan, tanpa terjadinya segregasi atau bleeding yang berlebih. Dengan komposisi yang baik dalam metode SCC ini, diharapkan dapat memberikan kemudahan dalam proses pembuatan beton dan dapat menghemat biaya pengerjaan. Dari tinjauan permeabilitas, perubahan struktur mikro akibat reaksi pozzolanic juga menurunkan permeabilitas sehingga HVFA - SCC lebih resisten dalam melawan penetrasi ion-ion yang dapat merusak beton (Andreas, 2017).

Berdasarkan latar berlakang diatas, memanfaatkan kekuatan yang dihasilkan dari campuran semen dengan fly ash bervolume besar pada cementitious, serta workability yang didapatkan dari beton SCC. Pada penelitian ini fokus masalah akan dilakukan pada pengujian besar kuat tarik HVFA-SCC dengan kandungan kadar fly ash sebesar 50\% dan $60 \%$. Dengan sampel pembanding berupa balok beton normal.

\section{LANDASAN TEORI}

\section{Self Compacting Concrete (SCC)}

SCC adalah suatu beton yang ketika masih berbentuk beton segar mampu mengalir melalui tulangan dan memenuhi seluruh ruang yang ada didalam cetakan secara padat tanpa ada bantuan pemadatan manual atau getaran mekanik. (Tjaronge et.al 2006 dan Hartono, et.al 2007).

SCC adalah beton non-segregasi yang sangat mudah mengalir dan dapat menyebar ke semua tempat, mengisi bekisting dan melewati tulangan tanpa getaran mekanis untuk konsolidasi. SCC memanfaatkan komposisi agregat yang digunakan, bentuk dan ukuran bahan campuran pasta serta kadar superplasticizer. Superplasticizer diperlukan untuk mendispersikan (menyebarkan) partikel semen menjadi merata dan memisahkan menjadi partikel-partikel yang halus sehingga reaksi pembentukan C-S-H (tobermorite) akan lebih merata dan lebih aktif (Angelina, 2012).

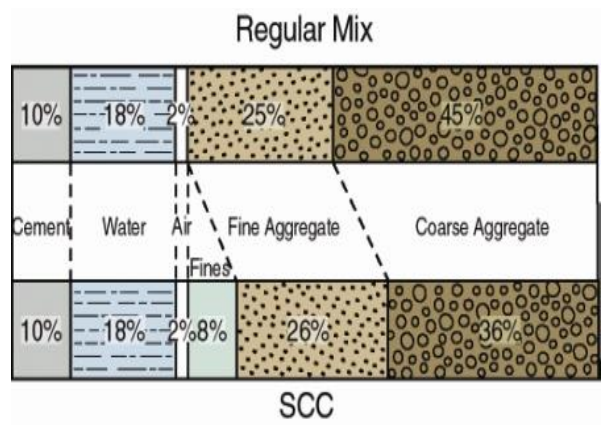

Gambar 1. Perbandingan proporsi campuran SCC, RCD dan beton konvensional

Namun beton SCC pun memiliki beberapa kelemahan, seperti yang dijelaskan oleh EFNARC Specification and Guidelines for Self-Compacting Concrete, 2002, Karena tingginya kandungan powder, beton SCC dapat menunjukan lebih banyak susut plastis atau creep, dari pada campuran beton biasanya. Karena itu aspek tersebut harus dipertimbangkan selama merancang dan menetapkan beton SCC. 


\section{High Volume Fly Ash (HVFA)}

Istilah beton $H V \mathrm{~F} A$ digunakan untuk mengenali bahan beton yang menggunakan fly ash sebagai pengganti semen dalam jumlah tinggi. Penelitian menunjukan bahwa beton $H V F A$ memiliki peningkatan yang signifikan dalam sifat mekanik dan durability dibanding beton konvensional. Beton HVFA memiliki modulus elastisitas yang lebih tinggi (En-Hua Yang et al, 2007).

High volume fly ash concrete (HVFAC) diartikan sebagai beton yang menggunakan fly ash sebagai bahan pozzolanic sebagai substituent semen dengan persentase fly ash $50 \%$ atau lebih dari berat total binder. Kelebihan beton tersebut adalah ramah lingkungan, ekonomis, memperlambat setting time, meningkatkan workability, durability, dan diharapkan meningkatkan kekuatan dari beton (Stefanus dan Howard, 2010).

Meskipun pemakaian fly ash tidak memberikan kekuatan awal beton, namun dengan masih berlangsungnya reaksi pozzolanic maka kekuatan beton akan meningkat dalam jangka waktu yang lama (Bilodeau and Malhotra, 2000, Nawy, 1996).

\section{Kuat Tarik Langsung}

Pengujian kuat tarik langsung dilakukan dengan metode uniaxial tensile test. Pengujian dilakukan dengan mengacu pada penelitian Faez Alhussainy, dkk, Direct tensile testing of Self-Compacting Concrete tahun 2016, pada bagian atas,baja drat pada luar beton di pasang rantai lalu dicengkram dengan penjepit pada UTM. Bagian bawah baja drat pada luar beton langsung dikaitkan pada penjepit grip UTM. Fungsi dari rantai ialah untuk tetap menjaga eksentrisitas pada saat beban tarik aksial diberikan pada beton.

Dalam perencanaan benda uji, pola kegagalan harus direncanakan sedemikian rupa sehingga kegagalan terjadi karena retak pada penampang normal benda uji. Untuk mengantisipasi hal ini selama percobaan digunakan baja drat dengan diameter yang cukup besar dan tegangan leleh fy yang cukup tinggi. Juga bond antara tulangan dan beton ditingkatkan, menambahkan sirip, atau cakram. Metode pengujian dapat dilihat pada gambar 2. sebagai berikut:

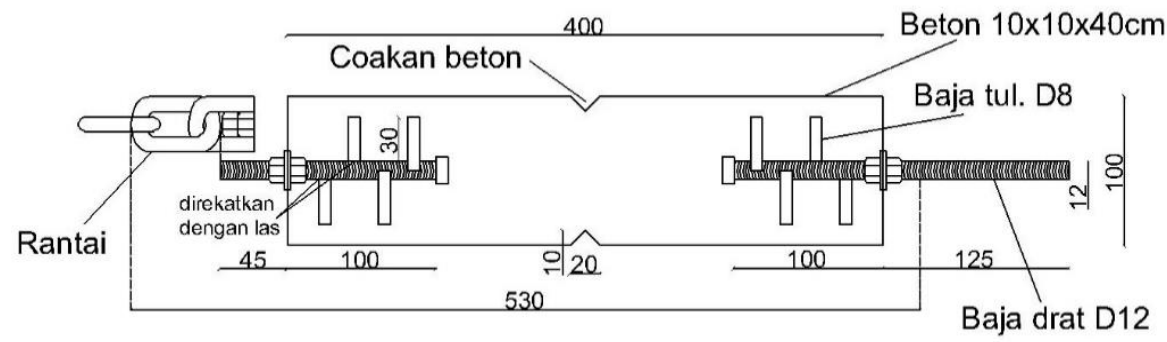

Gambar 2. Detail pengujian sampel kuat tarik langsung

Kuat tarik beton dengan pengujian ini dapat dihitung dari rumus :

$$
f_{t}=\frac{P}{A}
$$

dimana:

$f_{t}=$ kuat tarik langsung dalam $\mathrm{MPa}$

$\mathrm{P}=$ beban maksimum yang mampu ditahan dalam $\mathrm{kN}$

$\mathrm{A}=$ luas penampang efektif dalam $\mathrm{mm}^{2}$.

\section{Energi Fraktur Elastik Linear}

Redistribusi tegangan plastis terjadi akibat adanya retak mikro, sejalan dengan disipasi energi yang secara kuantitas menentukan laju keruntuhan struktur. Beton normal dengan kekakuan dan modulus elastisitas matriksnya lebih rendah dari kekakuan dan modulus elastisitas agregat, akibat beban, berpotensi mendisipasi energy seiring proses unloading. Keruntuhan material beton secara mendasar dapat digolongkan sebagai runtuh getas (brittle failure). Menurut Patty, 2013, Keruntuhan getas terjadi karena ketidakmungkinan terjadinya redistribusi tegangan plastis 
setelah pencapaian kuat tarik matriks. Energi Fraktur Elastik Linear (Gc) diartikan sebagai energy yang dibutuhkan untuk membentuk satu unit bidang retak.

Oleh Reinhardt (2013), Area di bawah kurva load-displacement diartikan sebagai energi fraktur, dan dapat dihitung dengan persamaan sebagai berikut :

$$
G_{c}=\frac{1}{2} f_{t}^{2} \frac{L}{E}
$$

dengan : $\quad G_{c}=$ energi fraktur elastik linear $(\mathrm{N} / \mathrm{m})$

$f_{t} \quad=$ kuat tarik maksimum $\quad\left(\mathrm{N} / \mathrm{m}^{2}\right)$

$\mathrm{L} \quad=$ volume per luas penampang $(\mathrm{m})$

$\mathrm{E} \quad=$ modulus Young $\quad\left(\mathrm{N} / \mathrm{m}^{2}\right)$

\section{Modulus Elastisitas}

Modulus Elastisitas adalah kemiringan kurva tegangan-regangan di dalam daerah elastik linear pada sekitar $40 \%$ beban puncak (ASTM STP 169 D Chapter 19, 1994). Dari grafik hubungan tegangan-regangan, modulus elastisitas tarik beton $(E c)$ yang dapat ditentukan dari regangan pada saat tegangan bernilai 0,4 ft yang diadopsi seperti penghitungan modulus elastisitas tekan beton yang diatur pada ASTM C-469 "Standard Test Method for Static Modulus of Elasticity".

\section{METODE}

Pada penelitian ini benda uji yang digunakan adalah balok beton berdimensi $10 \mathrm{~cm}$ x $10 \mathrm{~cm}$ x $40 \mathrm{~cm}$ yang yang ditanam baja drat pada sisi atas dan bawah, baja drat tertanam sepanjang $12,5 \mathrm{~cm}$, sedangkan baja drat yang keluar beton sepanjang $10 \mathrm{~cm}$. Benda uji terdiri dari 3 buah beton normal, 3 HVFA-SCC kadar $50 \%$ dan 3 HVFA-SCC kadar $60 \%$. Pengujian dilakukan dengan pembebanan dibawah load controlled test, dan diukur displacement-nya dengan menggunakan LVDT.

\section{HASIL DAN PEMBAHASAN}

Hasil Pengujian Material

Pengujian terhadap agregat kasar dilakukan pengujian berat jenis (specific gravity), keausan (abrasi) dan gradasi agregat kasar. Hasil pengujian agregat kasar dipaparkan dalam Tabel 1.

Tabel 1. Hasil Pengujian Agregat Kasar

\begin{tabular}{llccc}
\hline No & Jenis Pengujian & Hasil Pengujian & Standar & Kesimpulan \\
\hline 1 & Absorbtion & $2,1 \%$ & - & - \\
\hline 2 & Apparent Specific Gravity & $2,648 \mathrm{gr} / \mathrm{cm}^{3}$ & - & - \\
\hline 3 & Bulk Specific Gravity & $2,508 \mathrm{gr} / \mathrm{cm}^{3}$ & - & - \\
\hline 4 & Bulk Specific SSD & $2,561 \mathrm{gr} / \mathrm{cm}^{3}$ & $2,5-2,7 \mathrm{gr} / \mathrm{cm}^{3}$ & Memenuhi syarat \\
\hline 5 & Keausan Agregat & $26,920 \%$ & $<50 \%$ & Memenuhi syarat \\
\hline
\end{tabular}

Pengujian agregat halus dilakukan pengujian kadar lumpur, kandungan zat organik, specific gravity, gradasi agregat dan berat jenis. Hasil pengujian tersebut dipaparkan dalam Tabel 2.

Tabel 2. Hasil Pengujian Agregat Halus

\begin{tabular}{llccc}
\hline No & Jenis Pengujian & Hasil Pengujian & Standar & Kesimpulan \\
\hline 1 & Absorbtion & $1,937 \%$ & - & - \\
\hline 2 & Apparent Specific Gravity & $2,627 \mathrm{gr} / \mathrm{cm}^{3}$ & - & - \\
\hline 3 & Bulk Specific Gravity & $2,500 \mathrm{gr} / \mathrm{cm}^{3}$ & - & - \\
\hline 4 & Bulk Specific SSD & $2,548 \mathrm{gr} / \mathrm{cm}^{3}$ & $2,5-2,7 \mathrm{gr} / \mathrm{cm}^{3}$ & Memenuhi syarat \\
\hline 5 & Kandungan Lumpur & $4,5 \%$ & Maksimal $5 \%$ & Memenuhi syarat \\
\hline
\end{tabular}

Fly ash yang digunakan dalam penelitian ini berasal dari PLTU. Pengujian fly ash dilakukan di Laboratorium MIPA Terpadu Universitas Sebelas Maret untuk mengetahui kandungan kimia. Setelah dilakukan pengujian Jumlah kandungan $\mathrm{Al} 2 \mathrm{O} 3+\mathrm{SiO} 2+\mathrm{Fe} 2 \mathrm{O} 3$ adalah sebesar 64.17\% dengan kandungan Al2O3 sebesar 11.29 \%, SiO2 sebesar $31.76 \%$, Fe2O3 sebesar $21.12 \%$. Sedangkan kadar SO3 sebesar 1.67\% dan CaO sebesar 15.02\%. Sehingga 
menurut ASTM C-618 fly ash yang digunakan termasuk kedalam fly ash kelas C sedangkan menurut CSA A3001 termasuk fly ash tipe $\mathrm{Cl}$.

\section{Rancang Campur (Mix Design)}

Rancang campur (mix design) pada penelitian HVFA-SCC 50\%, 60\% dan beton normal dibuat untuk volume sebesar $1 \mathrm{~m}^{3}$. Rancang campur (mix design) dapat dilihat pada Tabel 3 sebagai berikut :

Tabel 3. Rancang Campur Beton High Volume Fly Ash - Self Compacting Concrete dan Beton Normal

\begin{tabular}{lccccccc}
\hline Kode & $\begin{array}{c}\text { Presentase } \\
\text { Fly Ash }\end{array}$ & $\begin{array}{c}\text { Semen } \\
\left(\mathbf{k g} / \mathbf{m}^{3}\right)\end{array}$ & $\begin{array}{c}\text { Fly Ash } \\
\left(\mathbf{k g} / \mathbf{m}^{3}\right)\end{array}$ & $\begin{array}{c}\text { Kerikil } \\
\mathbf{( k g / \mathbf { m } ^ { 3 } )}\end{array}$ & $\begin{array}{c}\text { Pasir } \\
\left(\mathbf{k g} / \mathbf{m}^{3}\right)\end{array}$ & $\begin{array}{c}\text { Air } \\
\left(\mathbf{l t} / \mathbf{m}^{3}\right)\end{array}$ & $\begin{array}{c}\text { Sp } \\
\left(\mathbf{l t} / \mathbf{m}^{3}\right)\end{array}$ \\
\hline HVFA28.50 & $50 \%$ & 250 & 250 & 773,70 & 870,30 & 145 & 8 \\
\hline HVFA28.60 & $60 \%$ & 200 & 300 & 771,32 & 867,62 & 145 & 8 \\
\hline NC28 & - & 450 & 0 & 944,69 & 660,31 & 220 & 0 \\
\hline
\end{tabular}

\section{Hasil Pengujian Beton Segar}

Pengujian HVFA-SCC terdiri dari Flow Table Test, L-Box Test, dan V-funnel Test, sedangkan beton normal dilakukan pengujian slump. Hasil pengujian tersebut disajikan dalam Tabel 4 sebagai berikut :

Tabel 4. Hasil Pengujian Beton Segar HVFA-SCC

\begin{tabular}{|c|c|c|c|c|}
\hline $\begin{array}{l}\text { Jenis Pen- } \\
\text { gujian }\end{array}$ & Parameter & $\begin{array}{c}\text { Hasil Pengujian Beton } \\
\text { Segar Fly Ash 50\% }\end{array}$ & $\begin{array}{c}\text { Hasil Pengujian Beton } \\
\text { Segar Fly Ash 60\% }\end{array}$ & $\begin{array}{c}\text { Persyaratan Beton SCC } \\
\text { (EFNARC 2002) }\end{array}$ \\
\hline \multirow{2}{*}{ Flow Table } & $\mathrm{D}(\mathrm{mm})$ & 700 & 700 & $600-700 \mathrm{~mm}$ \\
\hline & $\mathrm{t}_{50}(\mathrm{~s})$ & 3,16 & 3,11 & $2-5$ detik \\
\hline L-Box & h2/h1 & 0,94 & 0,94 & $0,8-1,0$ \\
\hline V-Funnel & $\mathrm{T}$ (detik) & 9,34 & 9,57 & $8-12 \mathrm{dt}$ \\
\hline
\end{tabular}

Sedangkan pada beton normal dilakukan pengujian slump dan didapat hasil adalah 10,5 cm.

\section{Hasil Pengujian Kuat Tarik Langsung}

Data - data yang diambil pada pengujian kuat tarik langsung meliputi data lendutan yang diperoleh dari pembacaan LVDT yang dipasang pada tengah bentang dan pada sisi depan dan belakang. Dan di plot menjadi grafik hubungan beban dengan lendutan rata-rata seperti dibawah.

\section{Grafik Load-Displacement \\ Uji Tarik Langsung}

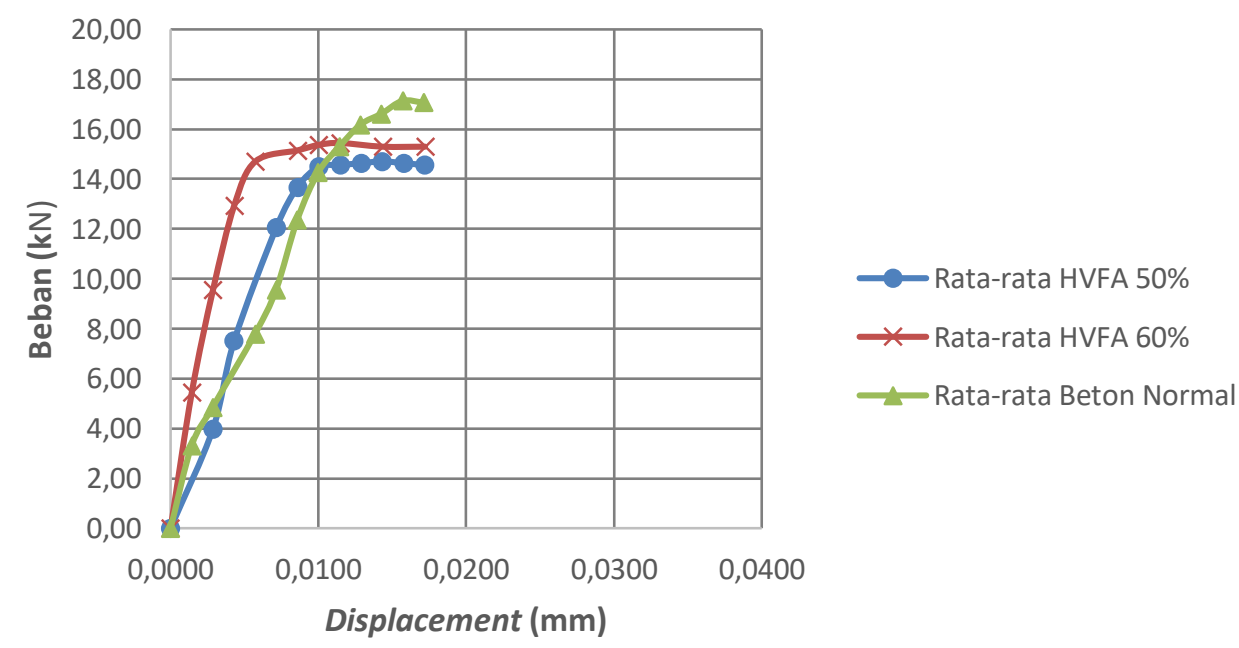

Gambar 3. Grafik hubungan beban-lendutan HVFA-SCC Kadar 50\%, 60\% dan Beton Normal 
Pada beton HVFA-SCC, baik kadar 50\% maupun 60\% juga mengalami hubungan yang linear antara beban dan perubahan panjang, namun tidak selandai dari grafik beton normal. HVFA-SCC memiliki kekakuan material yang lebih besar dari beton normal. Di awal pembebanan sampai mendekati beban puncak, perubahan panjang tidak banyak, sedangkan saat mendekati beban puncak sampai setelah beban puncak terlewati, terdapat perubahan panjang yang signifikan. Hal ini disebabkan oleh penambahan fly ash yang berfungsi sebagai filler mampu meningkatkan nilai daktilitas pada beton yang diuji saat umur 28 hari.

\section{Energi Fraktur Elastik Linear}

Hasil perhitungan Energi Fraktur Elastik Linear dapat dilihat pada tabel 5. berikut :

Tabel 5. Hasil Penghitungan Energi Fraktur Elastik Linear

\begin{tabular}{lc}
\hline Sampel & Gc $(\mathbf{N} / \mathbf{m})$ \\
\hline $\mathrm{NC}$ & 271,65 \\
\hline HVFA28.50 & 271,08 \\
\hline HVFA28.60 & 211,25 \\
\hline
\end{tabular}

Rata-rata energi fraktur elastik linear dari HVFA-SCC kadar 50\%, kadar 60\% dan beton normal berturut-turut $271,08 \mathrm{~N} / \mathrm{m}, 211,25 \mathrm{~N} / \mathrm{m}, 271,65 \mathrm{~N} / \mathrm{m}$. Nilai energi pada HVFA-SCC baik kadar 50\% maupun kadar $60 \%$ berada dibawah nilai energi beton normal. Meskipun perbedaan antara HVFA-SCC kadar 50\% dengan beton normal hanya sedikit, penggunaan fly ash dengan kadar yang lebih tinggi lagi akan semakin menurunkan nilai energi yang dibutuhkan untuk membuka satu unit bidang retak.

\section{Modulus Elastisitas}

Dengan cara menentukan nilai regangan pada saat tegangan bernilai $0,4 \mathrm{ft}$. Nilai modulus elastisitas hasil pengujian kuat tarik langsung HVFA-SCC kadar 50\%, 60\% dan beton normal dapat dilihat pada Tabel 6 sebagai berikut:

Tabel 6. Nilai Modulus Elastisitas HVFA-SCC kadar 50\%, 60\% dan beton normal

\begin{tabular}{lc}
\hline Sampel & Modulus Elastisitas (MPa) \\
\hline NC & 6.064 \\
\hline HVFA28.50 & 17.562 \\
\hline HVFA28.60 & 16.775 \\
\hline
\end{tabular}

Nilai modulus elastisitas terrendah dicapai oleh beton normal, yang dibuktikan dengan kemiringan grafik teganganregangan paling landai saat elastik linear.

\section{Nilai Perbandingan Kuat Tarik dengan Kuat Tekan}

Nilai perbandingan kuat tarik dengan kuat tekan pengujian kuat tarik langsung HVFA-SCC kadar 50\%, 60\% dan beton normal dapat dilihat pada Tabel 7 sebagai berikut:

Tabel 7. Nilai Perbandingan Kuat Tarik dengan Kuat Tekan HVFA-SCC kadar 50\%, 60\% dan beton normal

\begin{tabular}{lccc}
\hline Sampel & Kuat Tarik ft (MPa) & Kuat Tekan fc (MPa) & Ft/fc (\%) \\
\hline NC & 2,277 & 29,898 & 8 \\
\hline HVFA28.50 & 2,206 & 28,860 & 8 \\
\hline HVFA28.60 & 2,056 & 33,670 & 6 \\
\hline
\end{tabular}

\section{SIMPULAN}

Dari hasil pembahasan diatas dapat disimpulkan bahwa : 
1. Trend grafik load-displacement beton normal lebih landai dari HVFA-SCC kadar 50\% dan $60 \%$. Pertambahan panjang (displacement) yang tercatat pada HVFA-SCC kadar 50\% dan 60\% saat mendekati beban puncak sampai melewati beban puncak sangat signifikan, berbeda dengan beton normal yang tercatat hanya sedikit.

2. Rata-rata energi fraktur elastik linear pada HVFA-SCC baik kadar $50 \%$ maupun kadar $60 \%$ berada dibawah nilai energi beton normal. Bertambahnya kadar fly ash akan semakin menurunkan nilai energi yang dibutuhkan untuk membuka bidang retak.

3. Nilai Modulus Elastisitas (Ec) HVFA-SCC baik kadar 50\% dan 60\% lebih tinggi dibandingkan dengan beton normal.

4. Perbandingan nilai kuat tarik langsung dengan nilai kuat tekan (ft/f c) dari HVFA-SCC kadar 50\%, kadar 60\% dan beton normal berturut-turut $6 \%, 8 \%, 8 \%$. Nilai tersebut berada di bawah prediksi (ft/ $\mathrm{fc}$ ) pada umumnya, yaitu 9\% sampai 15\%. Dikarenakan pada pengujian tarik langsung seluruh penampang memikul tegangan tarik yang merata dan sama besar. Sehingga nilai yang didapat saat pengujian lebih mendekati nilai kuat tarik sebenarnya.

\section{UCAPAN TERIMAKASIH}

Ucapan terima kasih penulis sampaikan kepada Agus Setiya Budi, S.T., M.T. dan Dr. Eng. Halwan Alfisa Saifullah, S.T., M.T. selaku pembimbing yang dengan penuh kesabaran dan keikhlasan telah memberi koreksi dan arahan sehingga menyempurnakan hasil karya tulis penyusunan. Rasa terima kasih penulis sampaikan kepada tim skripsi Gabungan Super yang telah menyurahkan keringatnya untuk menggapai kelulusan bersama.

\section{REFERENSI}

Andreas Nur Hadi. 2017. The Effect of Fly Ash Content for Stress-Strain Behavior of High Volume Fly ash - Self Compacting Concrete (HVFA-SCC). Universitas Sebelas Maret Surakarta.

Anonim. 2002. "Specification and Guidelines for Self-Compacting Concrete". The European Federation of Specialist Construction Chemicals and Concrete Systems (EFNARC).

Anonim. 2005. "The European Guidelines for Self-Compacting Concrete Specification, Production and Use". The European Federation of Specialist Construction Chemicals and Concrete Systems (EFNARC).

ASTM, C. 127(2007) "Standard Test Method for Density. Relative Density (Specific Gravity), and Absorption of Coarse Aggregate."

ASTM, C. 131 "Test method for resistance to degradation of small-size coarse aggregate by abrasion and impact in the Los Angeles Macbine". In American Society for Testing and Materials (Vol. 100, pp. 19428-2959).

ASTM, C. 2001. 128-01. "Standard test method for density, relative density (specific gravity), and absorption of fine aggregate". United States: ASTM International.

ASTM, C. 2002. "136, Standard Test Method for Sieve Analysis of Fine and Coarse Aggregates". Annual Book of Standards, 4(02).

ASTM, C. 2003. 117. "Standard Test Method for Materials Finer than 75-um (No. 200) Sieve in Mineral Aggregates by Washing". Anl/llal Book ofIISTM S/(//](Iards, 4.

ASTM, C. 2014. 1611. "Standard test method for slump flow of self-consolidating concrete", ASTM Int, 1-6.

Davidovits, J. 1994. "Global warming impact on the cement and aggregates industries". World resource review, 6(2), 263278.

Faez Alhussainy, Hayder Alaa Hasan, Sime Rogic, M. Neaz Sheikh, Muhammad N.S. Hadi. 2016. "Direct tensile testing of Self-Compacting Concrete". School of Civil, Mining, and Environmental Engineering, University of Wollongong, Australia.

H.W. Reinhardt . 2013. "Factors affecting the tensile properties of concrete". University of Stuttgart. Germany

Isamu Yoshitake, Wenbo Zhang, Yoichi Mimura, Tadashi Saito. 2013. "Uniaxial tensile strength and tensile Young's modulus of fly-ash concrete at early age". Department of Civil and Environmental Engineering, Yamaguchi University, Tokiwadai 2-16-1, Ube, Yamaguchi 755-8611, Japan.

Kumar Mehta. 2006. High Volume Fy Ash Concrete for Sustainable Development. International Workshop on Sustainable Development and Concrete Technology. University of California.USA.

Longbang Qing*, Xinyu Shi, Ru Mu, Yuehua Cheng. 2018. "Determining tensile strength of concrete based on experimental loads in fracture test". College of Civil Engineering and Transportation, Hebei University of Technology, Tianjin 300401, China. 